Research Article

\title{
Application of Remote Sensing Technology in Sediment Estimating Entering the Dam Reservoirs due to Floods
}

\author{
Mohammad Hadian (ID $^{1}$ and Abolfazl Mosaedi ${ }^{2}$ \\ ${ }^{1}$ Faculty of Civil Engineering and Environment, Khavaran Institute of Higher Education, Mashhad, Iran \\ ${ }^{2}$ Water Engineering Department, Agriculture Faculty, Ferdowsi University of Mashhad, Mashhad, Iran \\ Correspondence should be addressed to Mohammad Hadian; m.hadian@profs.khi.ac.ir
}

Received 19 July 2021; Revised 5 August 2021; Accepted 9 August 2021; Published 14 September 2021

Academic Editor: S. Mahdi S. Kolbadi

Copyright (C) 2021 Mohammad Hadian and Abolfazl Mosaedi. This is an open access article distributed under the Creative Commons Attribution License, which permits unrestricted use, distribution, and reproduction in any medium, provided the original work is properly cited.

\begin{abstract}
The present study aimed to use remote sensing technology to estimate the concentration of particulate materials in the water entering the reservoirs of dams and consequently investigate the possibility of estimating the amount of sediment carried to the reservoir by flood during the life of the dam and its annual estimate. Using an advanced spectrometer device (ASD), the reflectance values of water containing different amounts of particulate sediments were measured in the range of $400-2500 \mathrm{~nm}$; then, these reflectance values were represented for the Landsat 8 satellite OLI bands using their spectral response functions. In the study of interband correlation with the number of particulate materials, band 2 (blue) and band 5 (near-infrared) were identified to prepare a specific and appropriate model. The specificity of the reflectance difference in the two abovementioned bands was presented as an exponential relationship between the concentration of particulate materials and spectral reflectance. In this model, the RMSE parameter for the maximum possible sediment concentration was equal to 1.57 and the parameter R2 was equal to 0.91 . In the second step, at the same time as the satellite passed, the area was visited and the sediments of the Ardak dam reservoir were sampled by recording their location. To complete this research, two measures were performed simultaneously, calculating the concentration of particulate materials sampled in the laboratory environment and their location on the image. Then, the number of particulate materials is estimated by taking into account the coordinates recorded from the images on which the relevant corrections have been made. According to the extracted exponential model, the results of estimating the concentration of particulate matter obtained from the model and Landsat satellite images with the concentration of particulate matter obtained from sampling showed its complete compatibility with field surveys to validate this research.
\end{abstract}

\section{Introduction}

Erosion, sediment transport, and sedimentation are one of the most important processes related to river geomorphology [1]. The result of local erosion effects is the nonlocal impact of sediment production. These effects can be divided into intrariver and extrariver effects [2]. Among the extrariver effects, the increase of water treatment costs, problems of industrial use of water due to wear of water turbines, and decrease of water cooling and sedimentation efficiency in irrigated lands can be mentioned [3]. The use of remote sensing in terrestrial observations is to better understand the world around us, what happens in those places, and the interactions between different systems of the earth
[4]. To observe the earth, the electromagnetic radiations (EMR) recorded by remote sensing were used [5]. These radiations are reflected or propagated by objects from land, oceans, or the surface of the ice or into the atmosphere, which are recorded by using aircraft or remote sensing equipment [6]. Remote sensing can be defined as "the measurement of electromagnetic waves emitted by an object by using a piece of equipment that has no contact with that object" [7]. The rivers of our country carry high sediment loads compared to the rivers of the world. This indicates the severity of erosion and poor condition of natural resources (excessive pressure on pastures, destruction of forest lands, and principles of improper agricultural use) in watersheds [8]. Remote sensing can be expressed in both radiation and 
particle flow modes. Erwin Schrödinger in 1957 stated that "all particles have radiative properties and inverted radiations can also exhibit particle properties." As a result, the propagation speed of electromagnetic radiations and the transfer velocity of photons in a vacuum are equal [9].

Figure 1 shows the output spectra of two black bodies (sun and earth) with different temperatures. This figure shows how the sun, which has a higher temperature than the earth, has the most radiation emitted at short wavelengths [10]. In addition, the earth has a temperature much lower than that of the sun. When at the highest point, it has the most radiation of waves with longer wavelengths. [11]. The information recorded by using satellite sensors may include errors in the geometry of the points and the measured dark number (DN) values of the pixels [12]. Radiometric errors are related to the dark number values recorded by using a sensor that depends on the measured rays of the object [13]. Some of the light shined on the surface of the water is absorbed by the water and scattered on some of it $[14,15]$. This action occurs on water molecules as well as other substances in water such as particles or solved materials [15]. The most important visual components in natural waters (lakes, oceans, and rivers) include soluble particulate matter and phytoplankton [16]. Each of these different components and materials has some effects on the process of absorption and distribution of energy from water [17]. Particulate matter is generally an insoluble organic matter resulting from plant rot; these substances are generally dark in colour and can change the colour of the water to yellowish-brown $[14,18]$. These particles generally determine both adsorption and dispersion properties in natural waters (Figure 2).

The amount of sediment and particulate matter along with running water is one of the major concerns in the design of hydraulic structures such as canals, valves, and dam turbines [2]. This issue is very important from other aspects such as maintaining soil quality in agricultural lands, environmental issues, and exploitation of water resources for drinking and industries [1]. Traditional methods can be used to estimate particulate materials in running water. In remote sensing data-based methods, the sensor that is most in line with the existing requirements and facilities is selected according to the size of the area and the accuracy required in estimating the amount of sediment with water [19]. Then, images related to the past and present are prepared and followed by a research team working on both field and software fronts until the result is achieved [20]. Numerous studies have been published to determine the concentration of particulate matter by remote sensing, but most of them are related to oceans and water in deep seas or the estimate of chlorophyll suspended at the surface of reservoirs [21-23]. One of the notable works in this regard is the research conducted by Giardino et al. [24] on the estimation of chlorophyll 2 in Lake Garda in Italy using satellite images of Hyperion. Another work performed based on the theoretical and physical relationships of sediments is the use of a simple model of transmitted radiation and remote sensing in muddy waters in the Venice Reservoir [25]. Adam et al. [26] performed all stages of their research in the laboratory by spectroscopy with different percentages of particulate

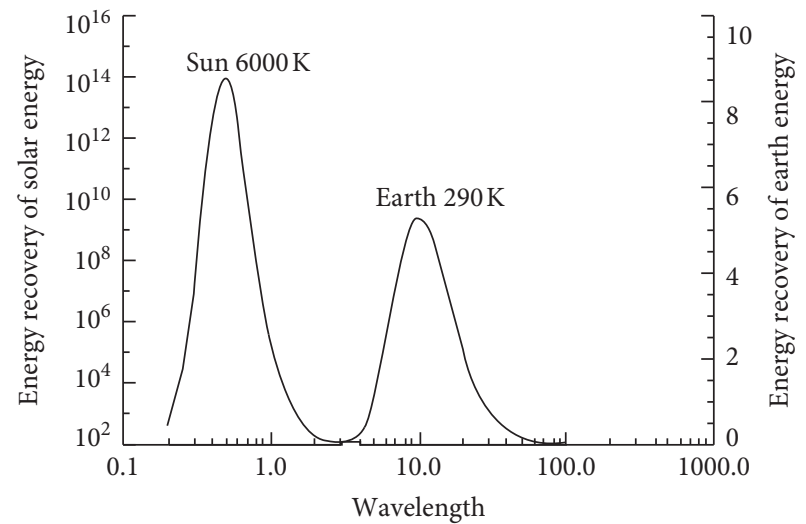

Figure 1: Spectral curve for a black body at the approximate temperature of the earth (K290) and the temperature of the sun (K6000) using the results of [7].

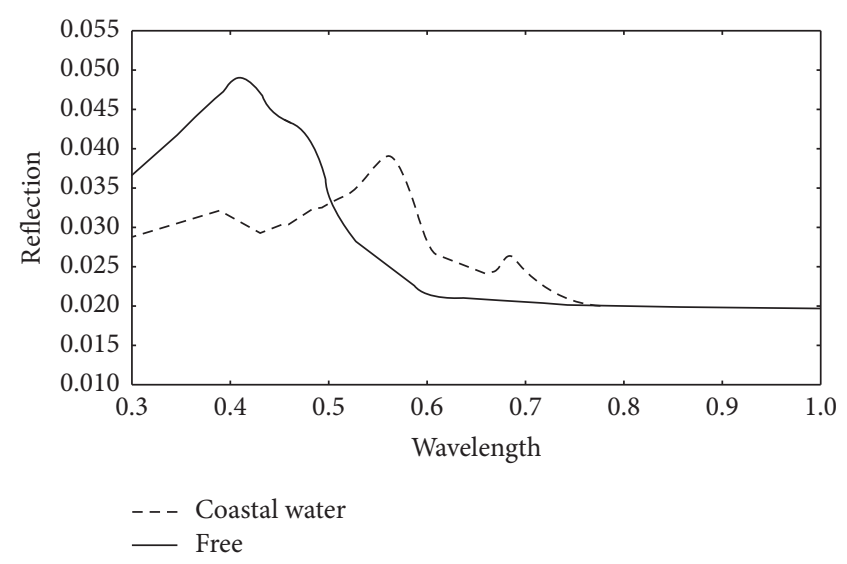

Figure 2: Seawater reflectance spectrum from 0.2 to 1 [14].

materials in the water, without using satellite imagery, obtained wavelength-reflection curves for different sedimentary materials (clay, fine sand particles, and algal material), and examined their presentation and behavioral characteristics at different wavelengths. Raul Espinoza and Jean-Micheal Martinez in 2013 conducted a study to estimate the sediment of the Madeira River in Brazil using MODIS satellite imagery [27].

\section{Materials and Methods}

2.1. Data and Study Area. To perform this research, information and assumptions are needed [28]. The Khorasan Regional Water Company was used to collect information about field visits and collect records and concentrations of particulate materials in previous floods [29]. The study area is the Ardak dam reservoir, located $60 \mathrm{~km}$ north of Mashhad in Khorasan Razavi Province (Figure 3). It is worth noting that the reason for choosing the dam is the proximity and availability of basic information and study records, low cost of sampling and cooperation of water officials in Khorasan Razavi Province, and also the importance of the dam due to the supply of drinking water in Mashhad. 


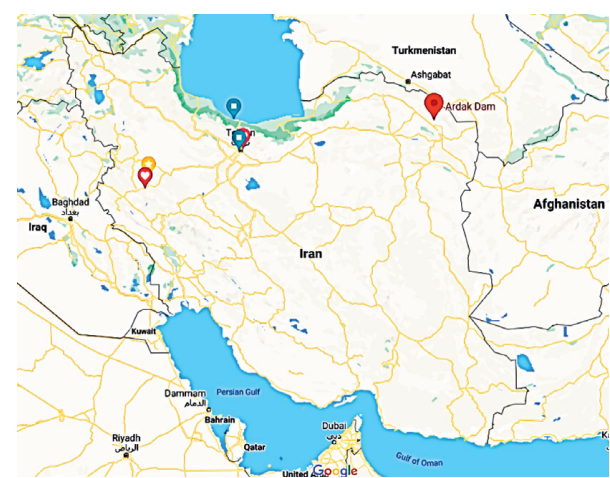

Figure 3: Location of the study area [29].

2.2. Preparation of Samples. Upon the arrangements made with the operation and security office of Ardak Dam, the researcher attended the dam reservoir and collected 5 bags of sediments produced through the settlement of suspended solids of the previous floods [30]. The samples were transferred to the laboratory. First, the sediments were completely dried under sunlight and passed through a sieve with a score of 40 \# and then packed and numbered in packages of $60 \mathrm{~g}$, $120 \mathrm{~g}$, and $1000 \mathrm{~g}$ with scales with an accuracy of $0.01 \mathrm{~g}$ [31]. The laboratory environment was isolated from all lights, and the windows were covered with black cloth [32]. The projector with the reader prop was installed at a distance of $40 \mathrm{~cm}$ above the water surface. At the beginning of the work, a standard white screen was used to calibrate the device; then, the first reading was taken after the pump was turned on and the water level was turbulent using the spectroradiometer device (ASD FieldSpec, Inc.) (Figures 4 and 5). In the first step, a $60 \mathrm{~g}$ sample of Ardak dam sediment is added to the test tank. This sample was first mixed with a small amount of tank water using an electric mixer and then added to the water inside the tank [33]. After the particulate materials were well mixed, the reading was observed by using a spectrometer and an image was taken by using a camera [34].

2.3. Atmospheric Correction. The most accurate method of capturing electromagnetic waves in the desired area by using the spectroradiometer is simultaneous with the passage of the satellite, through which the spectral behavior of the dominant phenomena can be captured [35]. For this purpose, radiation transfer models, such as flash algorithm, are used as a basis for researchers [36]. Ideally, it is Ls = Lt, but this does not happen in practice [37]. In atmospheric correction, we want to modify or eliminate $\mathrm{Lp}$ as much as possible because all the adverse effects are concentrated on Lp [10]. After making atmospheric corrections, the image is obtained as true colour, that is, as our eyes see in the environment [38]. Regarding the spectral behavior of the plant, it has fluctuating spectral behavior and the values of absorption and reflection inside it are very high and green light has the highest reflection in the visible range [39]. Sometimes, we want to see information from images that are not visible to the naked eye and it is called a false-colour composite system. FCC logic works in such a way that we

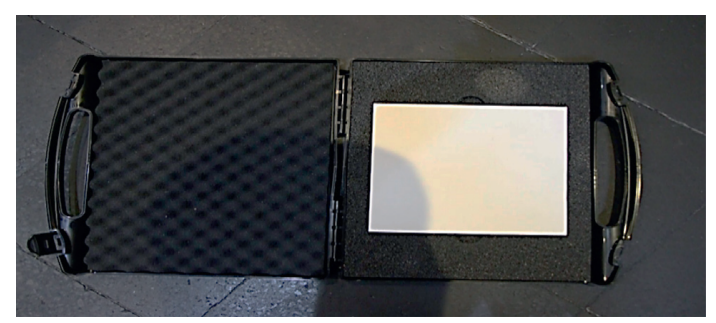

FIgURE 4: Standard white screen to calibrate the device.

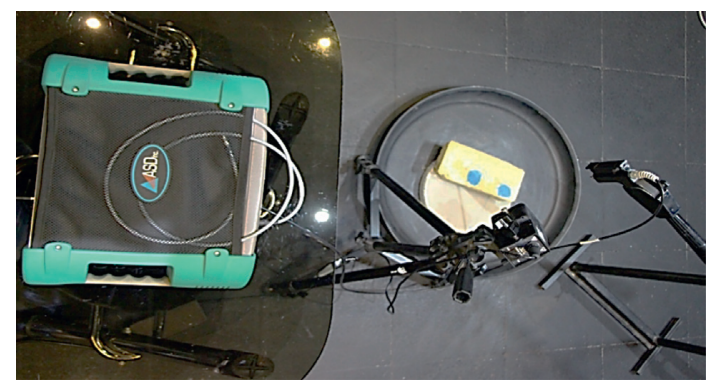

Figure 5: View of the spectroradiometer device and related equipment.

can better represent phenomena and extract information that is not normally recognizable (Figure 6).

\subsection{Zoning of Suspended Matter at the Surface of the Reservoir} Using Satellite Imagery. One of the most important applications of remote sensing is the possibility of zoning and separation of different materials using satellite images [41]. Different algorithms that exist in software such as ENVI can be used for this segmentation [42]. For example, the research conducted by Claudia [40] can be referred who recorded the water level of a dam reservoir based on the branch algorithm. The indicators are to show the changes and quality of water surface moisture, which is presented as an example of 5 of the most practical hygrometric indicators that can be used in Landsat, as described in Table 1, which is categorized by [43]. The research conducted by Mosocha et al. [44] showed that the accuracy of zoning and separation of wet and dry zones by the MNDWI index is $84 \%$ and the average reliability of the results is $89.5 \%$. Archory et al. [45] performed a study on hybrid indices to determine the threshold of wet and dry areas in Nepal and found that combining NDWI and NDVI indices is only useful for delineating pure water pixels [46].

\section{Results and Discussion}

3.1. Presenting an Empirical Model. The range of readings from $350 \mathrm{~nm}$ to $2500 \mathrm{~nm}$ was plotted on the horizontal axis and the reflection coefficient was plotted on the vertical axis [47]. For each experiment, 5 readings were recorded by using the device [48]. After arranging the results in the first step, averaging was performed from 5 readings and new diagrams were drawn in Excel. Then, the spectrum range from 400 to 1000 was selected and the corresponding reflectance curves were plotted separately, an example of which is shown in Figure 7. Figure 7(a) shows the output results of the 


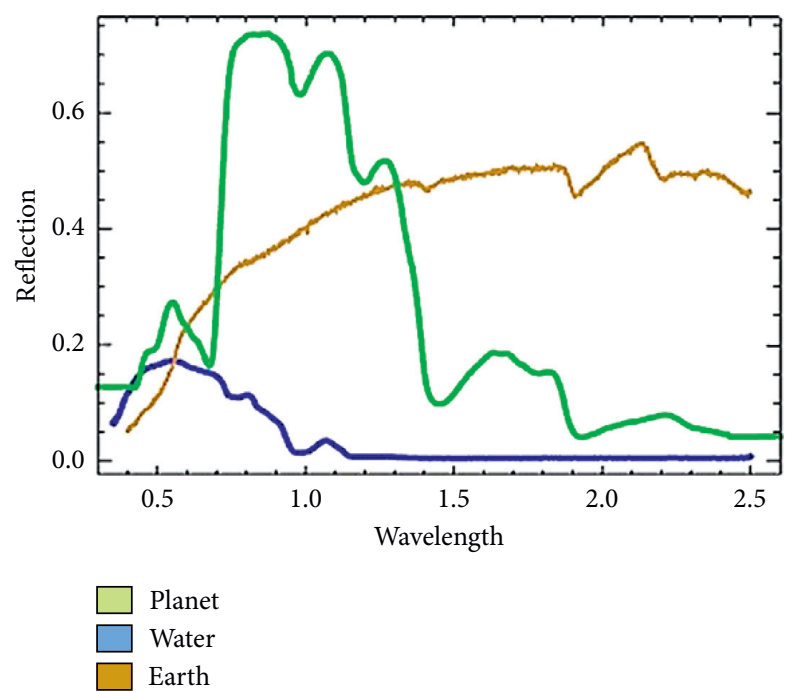

Figure 6: Standard reflection curves of pure water, soil, and plant [40].

TABLE 1: The indicators used for determining water quality in the Landsat satellite based on the general classification.

\begin{tabular}{lcc}
\hline Abbreviation & Description & Equation \\
\hline NDVI & Normalized difference vegetation index & NDVI $=$ NIR - Red/NIR + Red \\
NDWI & Normalized difference water index & NDWI $=$ Green - NIR/Green + NIR \\
MNDWI & Modified normalized difference water index & MNDWI $=$ Green - SWIR2/Green + SWIR2 \\
NDMI & Normalized difference moisture index & NDMI $=$ Red - NIR/Red + NIR \\
WRI & Water ratio index & WIR $=$ Green + Red $/$ NIR + SWIR2 \\
\hline
\end{tabular}

spectroradiometer up to $1000 \mathrm{~nm}$. In each extraction, five readings were taken simultaneously to reduce the instantaneous errors for the $2400 \mathrm{gr} /$ lit sedimentation rate [49]. Furthermore, Figure $7(\mathrm{~b})$ is the result of averaging the five initial impressions, which results in the elimination of possible errors during measurement to reduce systematic errors [50].

3.2. Evaluating the Laboratory Results. Examining the spectral curves shows that the reflectance values of R500 (in the blue and green range) of the spectral curve are higher than those of the R815 range (NIR) at low concentrations of suspended materials [51]. This trend is observed to a concentration of approximately $1.83 \mathrm{gr} / \mathrm{lit}$, and since then, the reflectance values of R815 exceed those of R500 [47]. Additionally, the study of spectral curves showed that the amount of reflection at the wavelength of R1515 from the concentration of $1944.44 \mathrm{gr} /$ lit does not increase significantly [53]. In other words, it is not possible to define a linear relationship for the entire range of samples tested by using this model [54]. The concentration of $20 \mathrm{gr} /$ lit is a relatively large amount, and increasing sediment from this amount is possible only in periods with high return due to the level of the Ardak dam basin and its vegetation and rocks (as well as field surveys). Similarly, where the maximum concentration is up to wavelengths of about $1000 \mathrm{~nm}$, the average of 5 readings per impression for each concentration of particulate materials was plotted in the range of 400 to $1000 \mathrm{~nm} \mathrm{[55].} \mathrm{Figure} 8$ simultaneously shows three graphs of the reflectance of different concentrations in the visible to infrared wavelengths [56]. In these three curves, the performance of the reflection curve of water with low to high concentrations of particulate materials is compared [57].

3.3. Building WSSSC Model. In the modeling stage, one of the three extractions was set aside to evaluate the model, respectively [58]. Studying the reflectance curves of Landsat OLI sensor bands showed that the reflectivity of band 5 with a center of $865 \mathrm{~nm}$ (R865) and band 2 with a center of $482.5 \mathrm{~nm}$ (R482.5) was selected as the bands that showed the highest and lowest reflectivity to the amount of particulate matter in the probable range of reservoir sediments [59]. After plotting the difference in reflectance values, it is observed that $\Delta R_{5-2}$ is negative for small amounts of particulate materials up to $4 \mathrm{gr} / \mathrm{lit}$. In addition, in the range of 4-20 gr/lit, changes have a linear behavior with the concentration of particulate materials, and behavior above $20 \mathrm{gr} /$ lit is completely nonlinear and exponential with great accuracy (Figure 9).

$$
\text { Wsssc }=4.4437 e^{\left(22.767 \Delta R_{5-2}\right)} .
$$

3.4. Results of Model Evaluation. To evaluate the WSSSC model, the obtained model should be validated [60]. For this purpose, this model is applied to the data that are not included in the modeling, which is about $33 \%$ of the data, and the model's output was compared with the extraction of the 


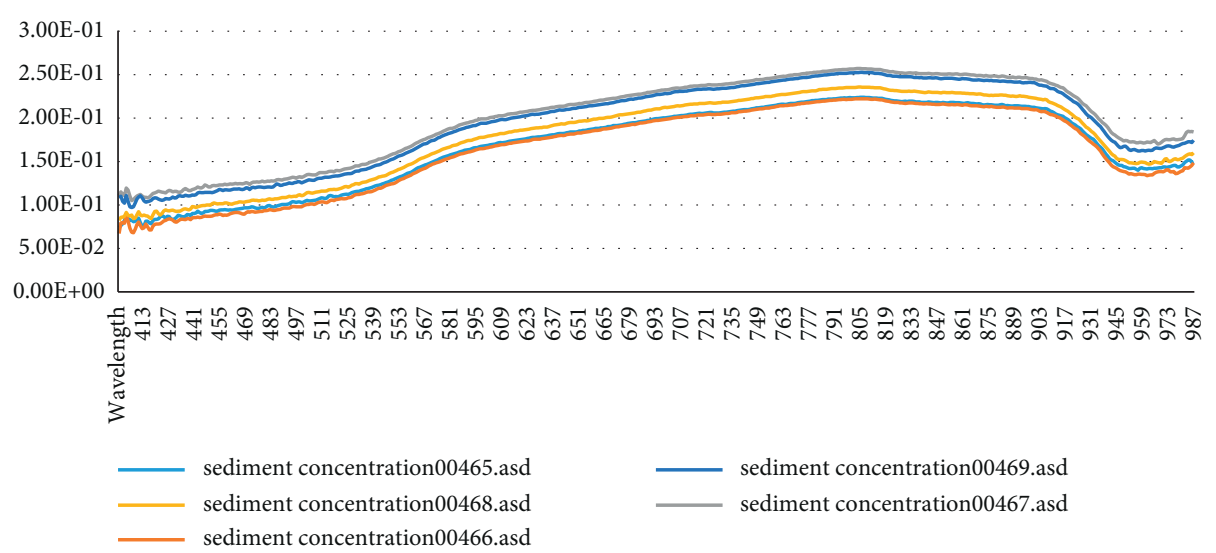

(a)

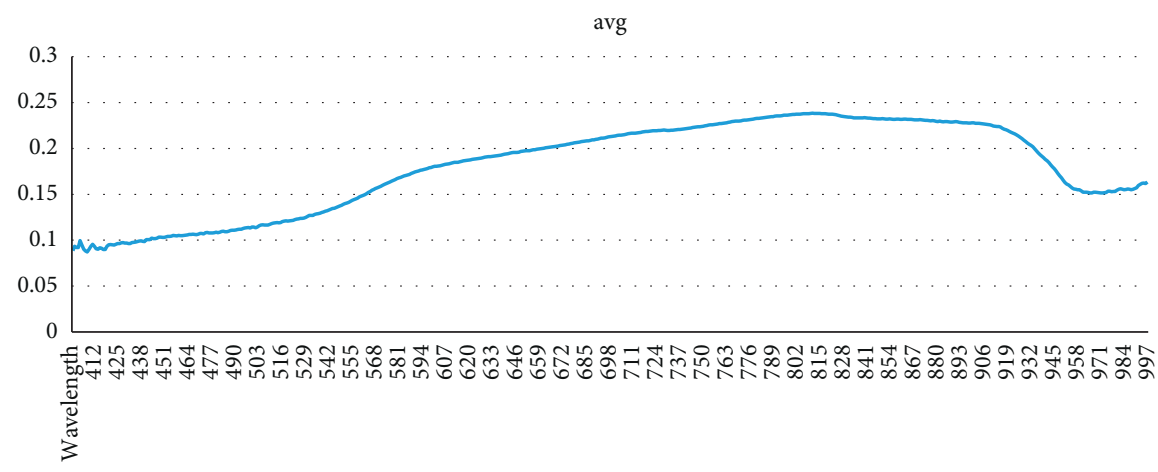

(b)

Figure 7: Spectral curve. (a) Five impressions of each sample. (b) Average readings.

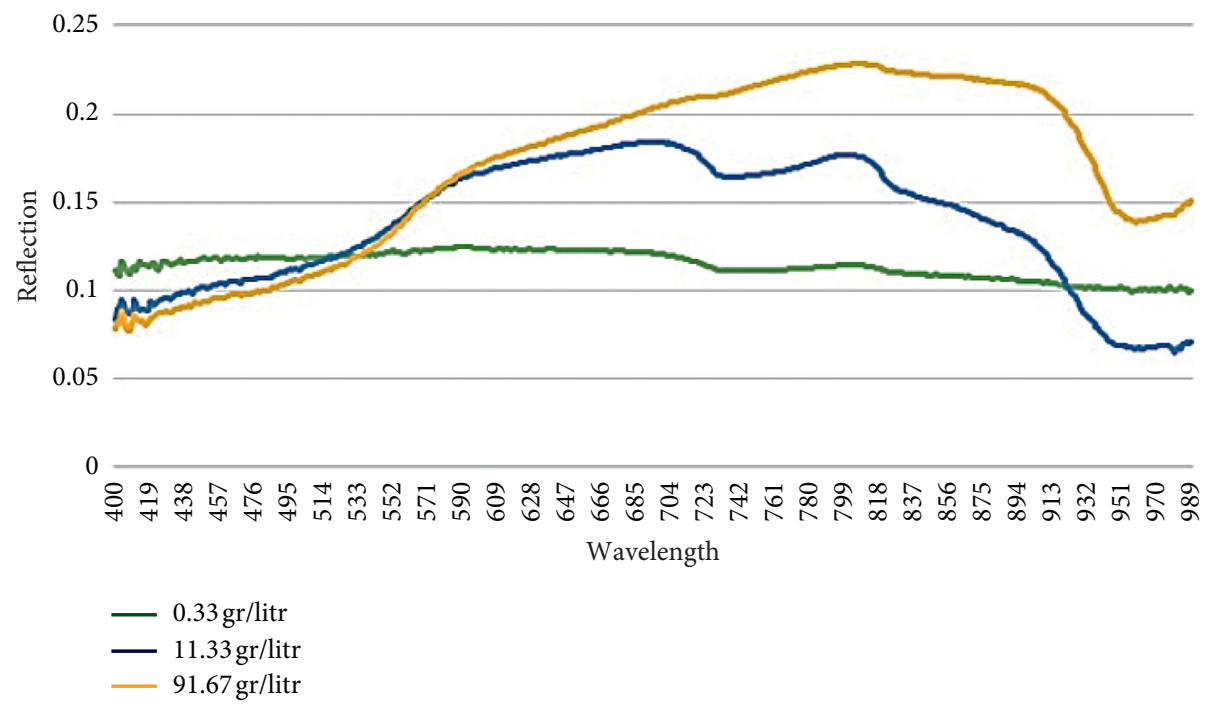

FIGURE 8: Display of reflectance values of samples at different concentrations of suspended solids on the surface.

real value of particulate materials in the laboratory (Figure 10). The results are shown in Figure 10, which shows a high correlation between the results [61]. The RMSE statistical parameter with the following equation (1) was used for evaluation [62]. In this equation, In this equation, the WSSSC model and WSSSC means values are the particulate sediment concentration and the actual amounts of sediment from laboratory harvesting, respectively. Also, $\mathrm{N}$ is the number of samples (Wang and $\mathrm{Lu}, 2010$ ) [63]. To evaluate the experimental model, two ranges of particulate materials were considered, one for the whole test range up to a concentration of about $100 \mathrm{gr} /$ lit which is a relatively high 


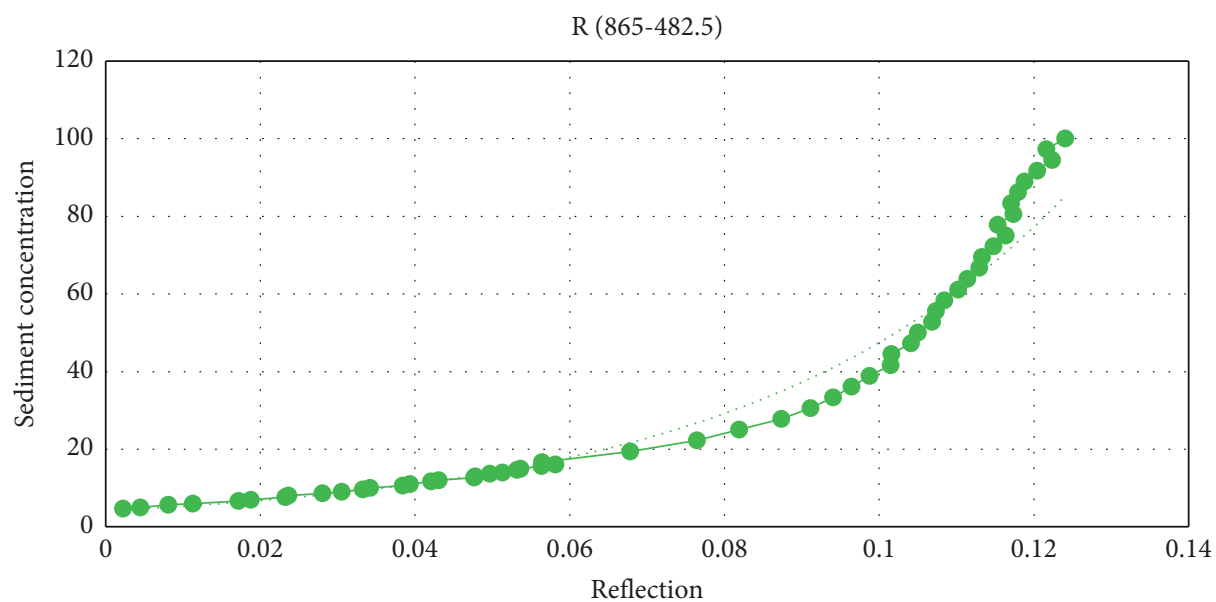

FIgURE 9: Relationship between suspended solids concentration in Landsat bands.

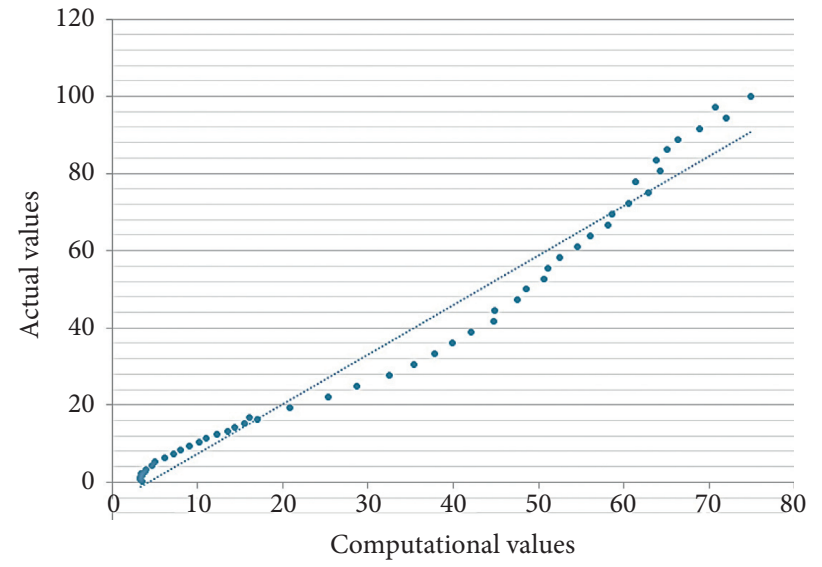

FIgURE 10: Comparison between the measured sediment concentrations and the output of the WSSSC model.

concentration and occurs in floods with a high return period, and the other up to a concentration of $22.2 \mathrm{gr} / \mathrm{lit}$ which results for the maximum possible amount of particulate materials $\mathrm{RMSE}=1.57$. Also, for the concentration of particulate materials in the second range, $\mathrm{RMSE}=0.24$ is obtained, indicating the ability of this relationship to model the number of particulate materials at the water surface with a small error [64].

3.5. Discussion on the Results of Laboratory Model. In the present study, the concentration of suspended sediments in the water surface with different values was estimated using the results of laboratory data and the spectral response function of Landsat 8 satellite bands [65]. For this purpose, the laboratory data related to the reflectivity of particulate materials in the water level of the dam reservoir were first analyzed [66]. Then, the results were simulated using the Landsat satellite spectral response function. Then, different models were studied, and finally, the "exponential" model related to the values of reflectance difference, which was more correlated with all values of this experiment, was selected. In the proposed model, $R 2=0.9915$ was obtained, indicating the accuracy of the proposed model. To evaluate the model, $33 \%$ of the data that were not used in model extraction were used [67]. Moreover, to evaluate the accuracy and efficiency of the model, the RMSE parameter was used for real and calculated values, the value of which is equal to 1.57 for the maximum possible concentration of particulate materials in the river of the project site and up to $22.2 \mathrm{~g} / \mathrm{l}$ for particulate materials, and for $95 \%$ of the particulate materials in the floods of this river, the value is equal to 0.24 . As mentioned in the introduction section, studies such as [24] have been conducted in the deep waters of the oceans and new research is needed for shallow waters.

\subsection{Extracting Information from Satellite Images}

3.6.1. Sampling Coinciding with the Passage of the Landsat Satellite. To apply the experimental relationship obtained through experiments in the laboratory environment, it is necessary to take field surveys at the same time as the satellite passes through the study area and also to download the satellite image [68]. Because the wavelengths required in this study are in the visible range, air cloud sampling is one of the problems that affect the quality of images. On the other hand, field visits should be as close as possible after the rain 


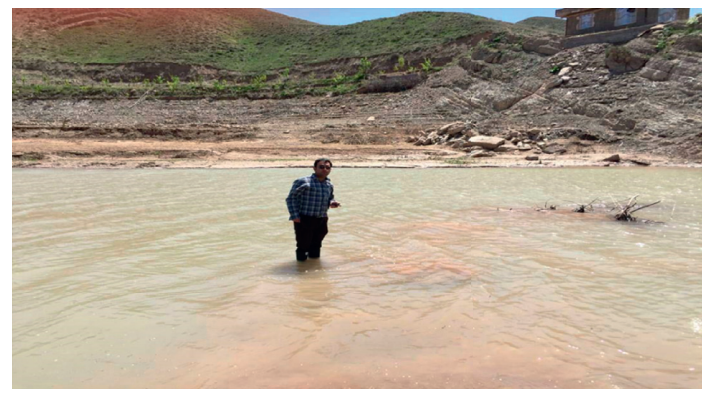

FIGURE 11: Picture of the sampling site of muddy water.

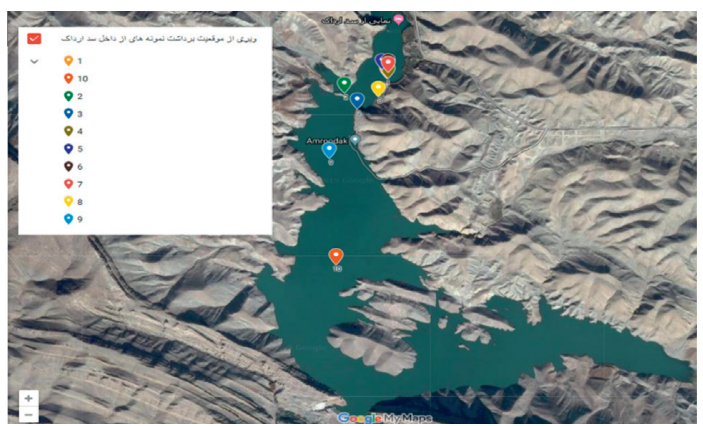

Figure 12: Sampling position in the dam reservoir.

TABLe 2: Results from the amount of computational sediment with the values sampled simultaneously with the satellite.

\begin{tabular}{lcc}
\hline Sample number & The amount of sediment according to the experimental relationship (gr/lit) & Sediment rate based on field surveys (gr/lit) \\
\hline 1 & 6.85 & 5 \\
2 & 14.18 & 11 \\
3 & 6.54 & 6 \\
4 & 6.69 & 5 \\
5 & 10.55 & 8 \\
6 & 9.63 & 7 \\
7 & 6.84 & 7 \\
8
\end{tabular}

when the concentration of particulate sediments is at the maximum possible amount. Finally, the visit on April 20, 2018, was one of the best possible cases when the sky was about $0.41 \%$ and the sediment concentration was relatively high due to the rains of the past few days. The first eight samples are related to spring and the end of April, when the vegetation is green and the amounts of particulate materials are calculated in the range of $5.72-11.72 \mathrm{gr} / \mathrm{lit}$, so the resulting values seem to be correct.

\subsection{Extracting the Results Using Satellite Images and Exper-} imental Laboratory Relationship. For this purpose, radiometric and atmospheric corrections were performed on the images, and the position of the points corresponding to the field sampling was determined. Then, the reflectance curve ( $Z$ curve) of that position was plotted. Because the reflection curve may not be related to suspended sediments due to human or GPS errors, first, the overall accuracy of the curve should be ensured, and after the accuracy of the curve has been determined, the reflection curve is stored along with the location of the sampling point at the dam reservoir location (Figures 11 and 12). Subsequently, the information should be extracted from the reflection curve. The amount of sediment obtained from extracting information from satellite images and the amount of sediment obtained from field samples prepared and calculated by using the heating device in the laboratory were recorded in the first and second columns, respectively.

3.8. Model Evaluation according to the Results of Satellite Images. For comparison, the actual sediment values from the sampling in a graph versus the sediment values from the experimental relation using satellite imagery and the RMSE value (root mean square error) were compared (Table 2). This value is equal to 1.93 based on equation (2). The above number indicates that the average calculated amount of sediment at $1.93 \mathrm{gr} / \mathrm{lit}$ is different from the actual amount of sediment in each measurement, so the question is whether 


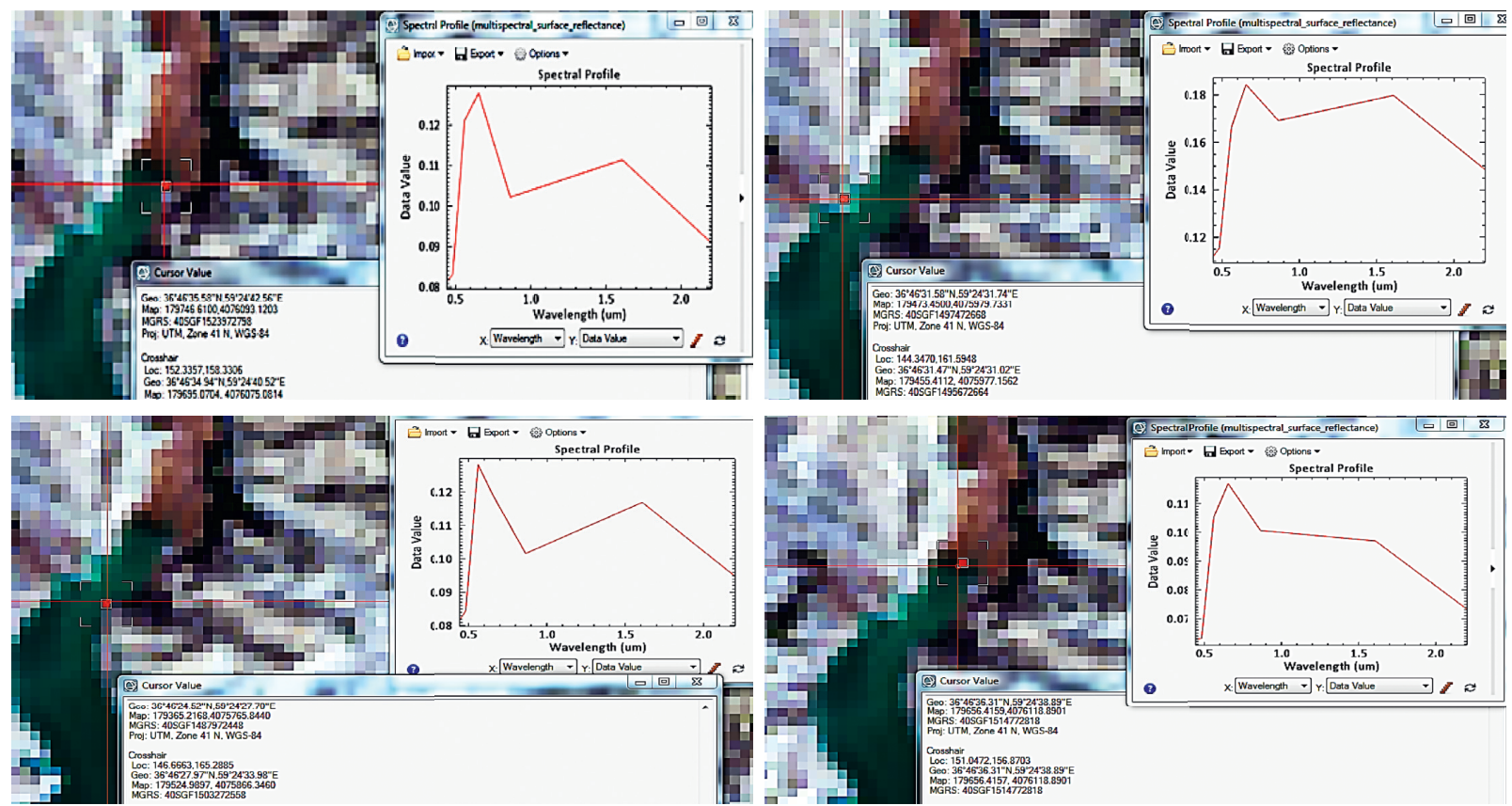

FIGURE 13: Spectral reflection curve related to harvest point numbers (1)-(4).

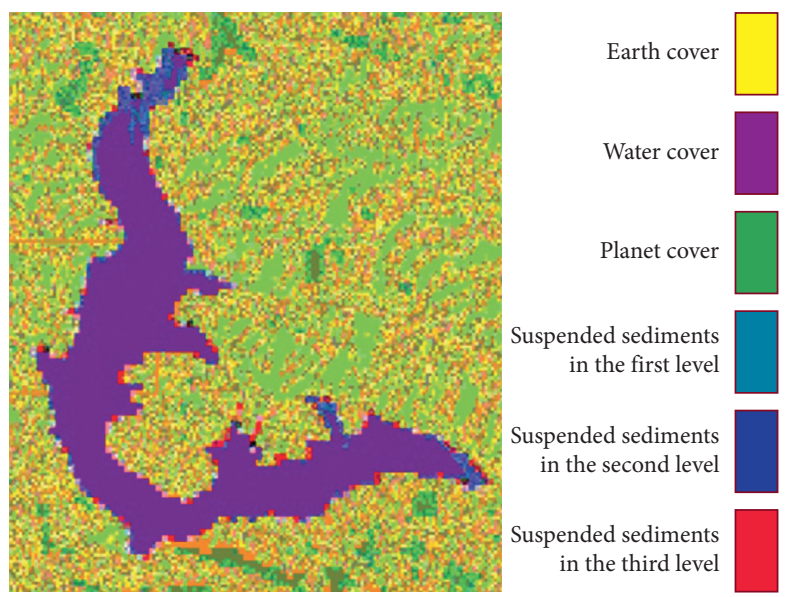

Figure 14: Thematic zoning of the study area.

this amount of error is acceptable or not. As mentioned in the articles, if the amount of this number is less than $33 \%$ of the average of the compared values, this error rate can be accepted with some considerations, and since the number 1.93 is less than one-third of the average sediment values (calculated and measured), the result can be considered acceptable [69]. Moreover, the percentage of this deviation in low sediment values may be significant, but the percentage of computational error is reduced for high sediment values according to the calculation of the RMSE value of this research (Figure 13). Since the significance of the present research is important for the amount of high particulate materials in severe floods that cause the document reservoir to be filled with sediments, its practical aspect increases with sampling in floods with high sediments (Figure 14).

$$
\text { Wsssc }=4.4437 e^{\left(22.767\left(\Delta R_{5-2}\right)\right)} .
$$

\section{Conclusion}

Significant funding from relevant organizations in different countries is allocated for this purpose, and many types of research have been conducted or are being performed by relevant experts and researchers to estimate the number of runoff sediments. Because these results form the basis of important decisions, they can sometimes have catastrophic consequences. Therefore, using other sciences to increase accuracy, reduce costs, and reduce the risk of death of the forces involved in this process is necessary and one of the most important tools in this regard is the use of remote 
sensing science or satellite technology. A common issue is the use of a model to extract information from satellite images. The researchers have used different methods to apply the model; some of which have used other models of researchers and localized its parameters. The necessity of research in the field of estimating particulate materials by preparing a specific model is felt only for the type of sediments in stable conditions for use in satellite images. In this research, the sediment concentration at the water level of Ardak dam reservoir in Mashhad was estimated as a case study and, finally, the study area was zoned using Landsat images, experiments were performed in the laboratory environment to prepare a specific model, field visits for sampling, and then radiometric and atmospheric corrections were performed on the images. The reflectivity of the models in the range of $2500-350 \mathrm{~nm}$ was measured using an ASD FieldSpec3 spectroradiometer with a spectral resolution of $1 \mathrm{~nm}$.

After averaging, the reflectance spectra of the samples in the range of 1000-400 $\mathrm{nm}$ were prepared. Then, the results of hyperspectral readings were converted to Landsat sensor band format and the exponential model was prepared based on the difference of bands 2 and 5 of the Landsat sensor with average values of R482.5 and R865. The RMSE index was 1.93. Since surface particulate materials have complex effects due to the material of this matter, bed effects, water surface distortion, and atmospheric effects on satellite data that cannot be abridged, the resulting error can be attributed to not considering one or more of the above. If the research is reiterated and sampled with high runoff seals and higher sediment concentrations, this zoning can be expanded and the accuracy of the output model can be increased. This research was conducted in two laboratory and field phases. In the laboratory phase, a special model was prepared using 90 samples of sediments docked at the entrance of the dam based on the site conditions. Then, this model was evaluated and the computational error rate was 1.57. This error is acceptable for high concentrations of particulate materials in large floods that carry significant volumes of sediment. Nevertheless, the specific presented model has a good accuracy according to the number of stages of spectroscopy test (60 cases) with different percentages of particulate materials and its evaluation (30 samples). The second step was to use this model in the field simultaneously with the satellite passage to estimate the concentration of particulate materials on the surface. At this stage, 8 samples of muddy water were prepared from different parts of the estuary, the results of which were calculated through the model in the laboratory and compared with each other.

\section{Data Availability}

Requests for access to these data should be made to the corresponding author (e-mail address: m.hadian@ profs.khi.ac.ir).

\section{Conflicts of Interest}

The authors declare that there are no conflicts of interest regarding the publication of this paper.

\section{References}

[1] M. S. Bejestan and A. Rezania, "Bed topography of river bend due to horizontal footing," in Environmental Hydraulics, pp. 813-818, CRC Press, Boca Raton, FL, USA, 2010.

[2] D. E. Walling and A. 1. Collins, Integrated Assessment of Catchment Sediment Budgets: A Technical Manual, p. 168p, University of Exeter, Department for International Development, Exeter, UK, 2000.

[3] S. Feiznia and M. Khosheghbal, "Investigating sensivity to erosion and sediment yield of formations in Latyan drainage basin," Iranian Journal of Natural Resources, vol. 56, no. 4, pp. 356-381, 2003.

[4] D. Antoine, J. M. Andr'e, and A. Morel, "Oceanic primary production: 2. Estimation at global scale from satellite (CZCS) chlorophyll," Global Biogeochemical Cycles, vol. 10, pp. 50-57, 1996.

[5] J. E. Tyler, "The Secchi disc," Limnology \& Oceanography, vol. 13, pp. 1-6, 1968.

[6] Q. Chen and Y. Zhang, "Water quality monitoring using remote sensing in support of the EU water framework directive (WFD): a case study in the gulf of Finland," Environmental Monitoring and Assessment, vol. 124, no. 1, pp. 157-166, 2007.

[7] P. M. Mather and M. Koch, Computer Processing of RemotelySensed Images: An Introduction, Published by Wiley, Hoboken, New Jersey, 4th edition, 2011.

[8] H. Rezazadeh, H. Aminikhah, and A. Refahi Sheikhani, "Stability analysis of Hilfer fractional differential systems," Mathematical Communications, vol. 21, no. 1, pp. 45-64, 2016.

[9] M.. F. O. khattab and B. J. Merkel, "Application of landsat 5 and landsat 7 images data for water quality mapping in mosul dam lake, northern irag," Arab J GeoSci, vol. 7, pp. 3557-3573, 2014.

[10] T. E. Jordan, D. Cornell, J. Miklas, and D. E. Weller, "Longterm trends in estuarine nutrients and chlorophyll, and short term effects of variation in watershed discharge," Marine Ecology Progress Series, vol. 75, pp. 121-132, 1991a.

[11] P. Kargar, A. Osouli, and T. D. Stark, "3D analysis of 2014 Oso landslide," Engineering Geology, vol. 287, Article ID 106100, 2014.

[12] J. A. Richards and X. Jia, Remote Sensing Digital Image Analysis. An Introductionp. 439, Fourth. edition, Springer Berlin Heidelberg, New York, 2006.

[13] S. M. Mousavimehr, O. A. Yamini, and M. R. Kavianpour, "Performance assessment of shockwaves of chute spillways in large dams," Shock and Vibration, vol. 2021, Article ID 6634086, 17 pages, 2021.

[14] J. T. Kirk, Light and Photosynthesis in Aquatic Ecosystemspp. 3-213, University Press, Great Britain, Cambridge, 2nd edition, 1994.

[15] A. Morel, B. Gentili, H. Claustre et al., "Optical properties of the "clearest" natural waters," Limnology \& Oceanography, vol. 52, no. 1, pp. 217-229, 2007.

[16] C. D. Mobley, F. Chai, P. Xiu, and L. K. Sundman, "Impact of improved light calculations on predicated phytoplankton growth and healthing in an idealized upwelling-down welling channel geometry," Journal of Geophysical Research: Oceans, vol. 120 , no. 2, pp. 875-892, 2015.

[17] O. A. Yamini, S. Hooman Mousavi, M. R. Kavianpour, and R. Safari Ghaleh, "Hydrodynamic performance and cavitation analysis in bottom outlets of dam using CFD modelling," Advances in Civil Engineering, vol. 2021, Article ID 5529792, 14 pages, 2021. 
[18] C. D. Mobley and M. Bass, "The optical properties of water," Handbook of OpticsMcGraw-Hill, USA, 2nd. edition, Chapter 3, pp. 43.3-43.56, 1995.

[19] A. Movahedi, M. R. Kavianpour, and O. A. Yamini, "Evaluation and modeling scouring and sedimentation around downstream of large dams," Environmental Earth Sciences, vol. 77, no. 8, 2018.

[20] M. R. Mobasheri and A. Hejazi, "Using satellite images for determination of critical points in polluted cities and their relation to lung cancer affection," Hakim Research Journal, vol. 17, no. 2, pp. 151-158, 2014.

[21] M. Babin, D. Stramski, GM. Ferrari et al., "Variations in the light absorption coefficients of phytoplankton, nonalgal particles, and dissolved organic matter in coastal waters around Europe," Journal of Geophysical Research Atmospheres, vol. 108, no. 7, 2003.

[22] C. E. Binding, D. G. Bowers, and E. G. Mitchelson-Jacob, "Estimating suspended sediment concentrations from ocean colour measurements in moderately turbid waters; the impact of variable particle scattering properties," Remote Sensing of Environment, vol. 94, pp. 373-383, 2005.

[23] H. R. Gordon and T. -Jrvz, "On the accuracy of determining light absorption by "yellow substance" through measurements of induced fluorescence," Limnology \& Oceanography, vol. 36, no. 4, pp. 777-786, 1973.

[24] C. Giardino, VE. Brando, AG. Dekker, N. Strömbeck, and G. Candiani, "Assessment of water quality in Lake Garda (Italy) using hyperion," Remote Sensing of Environment, vol. 109, pp. 183-195, 2007.

[25] Al-M. Nassrin Jassim Hussien, Al-F. Thair Al-Fatlawi Jabbar Mizhir, Y. O. Nariman, and Al-Z. Laith Shaker Ashoor, "Numerical analysis of seepage in earth-fill dams," Civil Engineering Journal, vol. 6, p. 7, 2020.

[26] S. Adam, A. De Backer, A. De Wever et al., "Bio-physical characterization of sediment stability in mudflats using remote sensing: a laboratory experiment," Continental Shelf Research, vol. 31, no. 10, pp. S26-S35, 2011.

[27] H. Wolpe, "Oil, war, and nationality," in Urban Politics in Nigeria, pp. 213-228, University of California Press, Berkeley, CA, USA, 2020.

[28] R. J. Davies-Colley, W. N. Vant, and R. J. Wilcock, "Lake water colour: comparison of direct observations with underwater spectral irradiance," Water Resources Bulletin, vol. 24, pp. 11-18, 1988.

[29] L. Furgani, M. A. Hariri-Ardebili, M. Meghella, and S. M. Seyed-Kolbadi, "On the dynamic capacity of concrete dams," Infrastructure, vol. 4, p. 57, 2019.

[30] A. G. Dekker and M. Donze, Imaging Spectrometry as a Research Tool for Inland Water Resources, Kluwer, Dordrecht, the Netherlands, 1994.

[31] A. G. Dekker, Ž. Zamurović-Nenad, H. J. Hoogenboom, and S. W. M. Peters, "Remote sensing, ecological water quality modelling and in situ measurements: a case study in shallow lakes," Hydrological Sciences Journal, vol. 41, no. 4, pp. 531-547, 1996.

[32] AG. Dekker, RJ. Vos, and S. W. M. Peters, "Comparison of remote sensing data, model results and in situ data for total suspended matter ž TSM/in the southern Frisian lakes," The Science of the Total Environment, vol. 268, no. 1, pp. 197-214, 2001.

[33] S. M. Seyed-Kolbadi, M. A. Hariri-Ardebili, M. Mirtaheri, and F. Pourkamali-Anaraki, "Instrumented health monitoring of an earth dam," Infrastructure, vol. 5, p. 26, 2020.
[34] C. G. Feldman, "Ocean color chlorophyll (OC) v6," Ocean Color Web, vol. 1, 2013 Retrieved September 06, 2013, from http://oceancolor.gsfc.nasa.gov/REPROCESSING/R2009/ocv $6 /$.

[35] H. R. Gordon and A. Y. Morel, Remote Assessment of Ocean Color for Interpretation of Satellite Visible Imagery. A Review, p. 114, Springer-Verlag, New York, 1983.

[36] H. R. Gordon, O. B. Brown, and M. M. Jacobs, "Computed relationships between the inherent and apparent optical propierties of a flat, homogeneous ocean," Applied Optics, vol. 14, pp. 417-427, 1975.

[37] J. F. R. Gower, L. Brown, and G. A. Borstad, "Observation of chlorophyll fluorescence in west coast waters of Canada using the MODIS satellite sensor," Canadian Journal of Remote Sensing, vol. 30, no. 1, pp. 17-25, 2005.

[38] S. Q. Kidder and T. H. Vonder Haa, Satellite Meteorology: An Introduction, Academic Press, Cambridge, Massachusetts, 1995.

[39] J. T. Kirk, "A Monte Carlo study of the nature of the underwater light field in, and the relationships between optical propierties of turbid yellow waters," Australian Journal of Marine \& Freshwater Research, vol. 32, pp. 517-532, 1981.

[40] C. Piptone, D. Moltese, and L. Lobrotto, Monitoring Water Surface and Level of a Reservoir Using Different Remote Sensing Approach via GNNS, Department of civil, Enviromental, Aerospace, Materials Engineering university degli studi di Polermo, Italy, 2018.

[41] S. Y. Kotchenova, E. F. Vermote, R. Matarrese, and F. J. Klemm, "Validation of a vector version of the $6 \mathrm{~S}$ radiative transfer code for atmospheric correction of satellite data. Part I: path radiance," Applied Optics, vol. 45, no. 26, pp. 67626774, 2006, Retrieved September 05, 2013, from http://www. ncbi.nlm.nih.gov/pubmed/16926910.

[42] R. M. Letelier and M. R. Abbott, "An analysis of chlorophyll fluorescence algorithms for the Moderate Resolution Imaging Spectrometer (MODIS)," Remote Sensing of Environment, vol. 58, no. 2, pp. 215-233, 1996.

[43] J. T. Kelly and A. M. Gontz, "Using GPS-surveyed intertidal zones to determine the validityof shorelines automatically mapped by Landsat water indices," Earth obs Geo information, vol. 65, pp. 92-104, 2018.

[44] M. mosocha, T. Dube, M. Mokor, and F. Jacob, "Surface water bodies mapping in Zimbabwe using Landsat 8 OLI multi spectral imagery: a comprison of multiple water in dices," Physics and Chemistry of the Earth, vol. 106, pp. 63-67, 2018.

[45] T. D. Archory, A. Subedi, and H. L. Dong, Evalution of Water Indices or Surface Water Extraction in a Landsat 8 Scene of Nep 06, 2018.

[46] T. Lillesand, R. Kiefer, and J. Chipman, Remote Sensing and Image Interpretationpp. 610-621, John Wiley \& Sons, 6th edition, 2008.

[47] A. Lyapustin, "Radiative transfer code SHARM-3D for radiance simulations over a on-Lambertian nonhomogeneous surface: intercomparison study," Applied Optics, vol. 41, pp. 5607-5615, 2002.

[48] S. K. Mc Feeters, "The use of normalized diffrence water index (NDWI) in the delineation of open water features," International Journal of Remote Sensing, vol. 17, pp. 1425-1432, 1996.

[49] A. Morel, "Optical modeling of the upper ocean in relation to its biogenous matter content (case 1 water)," Journal of Geophysical Research, vol. 93, pp. 10,749-10,768, 1988.

[50] J. H. Morrow, B. H. White, M. Chimiente, and S. Hubler, "A bio-optical approach to reservoir monitoring in Los Angeles. 
limnoology and lake management," Advances in Limnology, vol. 55, pp. 171-191, 2000.

[51] R. A. Neville and J. F. R. Gower, "Passive remote sensing of phytoplankton via chlorophyll a fluorescence," Journal of Geophysical Research, vol. 82, pp. 3487-3493, 1977.

[52] J. E. O'Reilly and Coauthors, SeaWiFS Postlaunch Calibration and Validation Analyses, Part 3. NASA Tech. Memo. 2000206892, S. B. Hooker and E. R. Firestone, Eds., vol. 11, p. 49, NASA Goddard Space Flight Center, 2000.

[53] J. E. O’Reilly, S. Maritorena, B. G. Mitchell et al., "Ocean color chlorophyll algorithms for SeaWiFS," Journal of Geophysical Research, vol. 103, no. C11, Article ID 24937, 1998.

[54] C. Ostlund, P. Flink, N. Strombeck, and D. Pierson, "Mapping of the water quality of Lake Erken, Sweden, from imaging spectrometry and landsat thematic mapper," The Science of the Total Environment, vol. 268, no. 1, 2001.

[55] H. H. Poole and W. R. G. Atkins, "Photoelectric measurements of submarine illumination throughout the year," Journal of the Marine Biological Association U. K.vol. 16, pp. 297-324, 1929.

[56] J. F. Schalles, "Chapter 3 Optical remote sensing techniques to estimate phytoplankton chlorophyll a concentrations in coastal waters with varying suspended matter and CDOM concentrations," in Remote Sensing of Aquatic Coastal Ecosystem Processes: Science and Management Applications, pp. 27-79, Springer, Berlin/Heidelberg, Germany, 2006.

[57] J. F. Schalles, A. A. Gitelson, Y. Z. Yacobi, and A. E. Kroenke, "Estimation of chlorophyll a from time series measurements of high spectral resolution reflectance in a eutrophic lake," Journal of Phycology, vol. 34, pp. 383-390b, 1998.

[58] R. A. Schowengerdt, Remote Sensing, Models and Methods for Image Processingp. 522, Second. edition, Academic Press, Boston, 1997.

[59] K. Stammes, S. C. Tsay, W. Wiscombe, and I. Laszlo, DISORT, a Generalpurpose FORTRAN Program for Discrete-OrdinateMethod Radiative Transfer in Scattering and Emitting Layered media: Documentation of Methodology, version 1.1, 2000.

[60] Usgs, Earth Observing 1 (EO-1) Frequently Asked Questions, Retrieved August 20, 2013, from https://eo1.usgs.gov/faq/ question?id=21, 2011.

[61] R. E. Villaro and J. Michel Martinez, “A study of sediment transport in the Moderia River, Brazil, using modis remote sensing images," Journal of fouth American Earth Science, vol. 44, pp. 45-54, 2013.

[62] V. Volpe, S. Silvestri, and M. Marani, "Remote Sensing of Environment Remote sensing retrieval of suspended sediment concentration in shallow waters," Remote Sensing of Environment. Elsevier Inc.vol. 115, no. 1, pp. 44-54, 2011a, Available at: http://dx.doi.org/.

[63] J. J. Wang and X. X. Lu, "Estimation suspended sediment concentration using Terra MODIS: an example from the lower yangtze River, China," The Science of the Total Environment, vol. 408, pp. 1131-1138, 2010.

[64] P. J. Werdell and S. W. Bailey, "An improved in-situ biooptical data set for ocean color algorithm development and satellite data product validation," Remote Sensing of Environment, vol. 98, no. 1, pp. 122-140, 2005.

[65] P. J. Werdell and C. Proctor, "NOMAD: NASA bio-optical marine algorithm dataset," SeaBASS, vol. 1, 2013 Retrieved July 21, 2013 from http://seabass.gsfc.nasa.gov/wiki/article. cgi? article=NOMAD.

[66] T. T. Wynne, R. P. Stumpf, M. C. Tomlinson et al., "Relating spectral shape to cyanobacterial blooms in the laurentian great lakes," International Journal of Remote Sensing, vol. 29, no. 12, pp. 3665-3672, 2008.

[67] H. Xu, "Modification of normalized difference water index (NDWI) to enhance open water features in remotely sensed imagery," International Journal of Remote Sensing, vol. 27, no. 14, pp. 3025-3033, 2006.

[68] Y. Zhang, J. Pulliainen, S. Koponen, and M. Hallikainen, "Application of an empirical neural network to surface water quality estimation in the Gulf of Finland using combined optical data and microwave data," Remote Sensing of Environment, vol. 81, pp. 327-336, 2002.

[69] S. Shadpoor, A. Pirouzi, H. Hamze, and D. Mazaheri, "Determination of bodenstein number and axial dispersion of a triangular external loop airlift reactor," Chemical Engineering Research and Design, vol. 165, pp. 61-68, 2021. 